\title{
PRINCÍPIOS DA TIPOGRAFIA CINÉTICA: um novo olhar
}

\author{
Volnei Antônio Matté \\ Universidade Federal de Santa Maria \\ volnei.a.m@gmail.com \\ Mariane Alves Rodrigues \\ Universidade Federal de Santa Maria \\ marianealvesrodrigues@gmail.com \\ Robson Godoy da Rosa \\ Universidade Federal de Santa Maria \\ robsongodoydarosa@gmail.com \\ Marcos Brod Junior \\ Universidade Federal de Santa Maria \\ brodjr74@gmail.com \\ Ricardo Brisólla Ravanello \\ Universidade Federal de Santa Maria \\ ricardoravanello@yahoo.com
}

\begin{abstract}
Resumo: A tipografia é um elemento central dos processos de comunicação do design gráfico, com um crescente interesse no estudo e desenvolvimento tipográfico. Nesse sentido, pela união das mídias digitais com a tipografia, tem-se a área da tipografia cinética que trata desses processos de comunicação em movimento. Este artigo apresenta um estudo que busca compreender a tipografia cinética e conhecer suas potencialidades em projetos para dispositivos móveis digitais (tablets). Para atingir seu objetivo o artigo apresenta um panorama geral da tipografia cinética; aborda possibilidades de criação utilizando esse tipo de comunicação interativa e culmina com a elaboração de um modelo de estudo dos princípios da tipografia cinética. Reforçamos a importância e os benefícios de se utilizar novas tecnologias no ambiente educacional.
\end{abstract}

Palavras-chave: animação, tipografia, tablets.

Typography is a central element of the communication processes of graphic design, with a growing interest in the typographic study and development. In this sense, the joining of digital media with typography, we have the area of kinetic typography that approaches these communication processes in motion. This article presents a study that seeks to understand kinetic typography and understand their potential in projects for mobile devices 
(tablets). To achieve its goal the paper presents an overview of kinetic typography; discusses creative possibilities using this type of interactive communication and culminates with the development of a model study of the principles of kinetic typography. At the end the intent is to reinforce the importance and benefits of using new technologies in the educational environment.

Keywords: animation, typography, tablets.

\section{INTRODUÇÃO}

Aprimorar as ferramentas de comunicação é uma exigência da sociedade atual. Como Lupton (2006, p. 75) argumenta, "nessa tão falada era da sobrecarga de informações, as pessoas continuam podendo processar uma só mensagem de cada vez". Vivencia-se um momento de grande volume de informações. Cada vez mais a população é exposta a um mundo repleto de mensagens que ninguém pediu para ver (BRINGHURST, 2005), o que gera demanda por tecnologias capazes de se comunicar no ritmo que os usuários desejam sem deixar de lado a eficiência na comunicação.

Dentro desse contexto tumultuado surgiram os tablets, dispositivos móveis de leitura e acesso a informações digitais, com características como portabilidade, conectividade e conforto, que trouxeram novas possibilidades para o Design, principalmente no que diz respeito a novas formas de se comunicar, transmitindo mensagens de maneira clara, intuitiva e efetiva. A tipografia cinética (também conhecida como tipografia em movimento) se mostra uma grande oportunidade de exploração comunicacional da tipografia, uma vez que seu caráter não é apenas verbal, mas também visual, o que amplia num grande leque de possibilidades de interação em interfaces digitais. Ina Saltz (2010) ressalta que textos que se comportam como imagens são entendidos com maior facilidade, uma vez que atingem vários filtros perceptivos - visual, emocional e intelectual - ao mesmo tempo.

Este artigo busca compreender as potencialidades do uso da tipografia cinética em interfaces para dispositivos móveis digitais (tablets). Para isso, são apresentados o panorama geral da área e as possibilidades de criação que os designers têm a sua disposição nesse tipo de projeto. $O$ artigo culmina com a elaboração de um modelo de estudo dos princípios da tipografia cinética que foca nas questões projetuais da tipografia, deixando de lado a parte puramente técnica dos softwares, tão abordada por outros estudos. Ao final espera-se reforçar a importância e os benefícios de se utilizar novas tecnologias interativas no ambiente educacional.

\section{DESENVOLVIMENTO}

Os estudos a respeito da tipografia cinética ainda são escassos, sendo que até mesmo sua conceituação ainda carrega muitas dúvidas. De uma maneira simples e objetiva pode-se definir tipografia cinética como uma animação em que o principal, senão o único elemento visual da composição é a tipografia. Nesse tipo de animação a tipografia vai além de suas funções habituais, e serve não só como elemento de comunicação verbal, mas também como elemento de comunicação visual. Uma das abordagens mais aceitas a respeito da verbalização do que é a tipografia cinética é 
dada por Barbara Brownie (2007), que propõe uma divisão da tipografia cinética em "tipografia em movimento" e "tipografia fluida".

\begin{abstract}
Nos exemplos de tipo em movimento, só há a mudança em uma escala global, mudança no leiaute global. O que a maioria das teorias de tipografia cinética não conseguiu analisar de forma significativa é a mudança em uma escala local, a mudança na letra individual. A letra pode ser cinética sem nunca mover-se, [...] Isso pode ser encaminhado para a tipografia como fluído. (BROWNIE, 2007, p. 1-2, tradução nossa)
\end{abstract}

Independente das questões terminológicas é consenso entre os autores que a adição de temporalidade a tipografia aumenta suas possibilidades comunicacionais e expressivas, sendo este um dos principais motivos para a tipografia cinética ser considerada uma nova forma de comunicação, muito mais adequada às exigências atuais, sejam elas tecnológicas (representadas pelo suporte a tecnologias cada vez mais avançadas que os dispositivos oferecem) ou socioculturais (representadas pela crescente necessidade social de aprimorar os laços de comunicação entre o suporte de leitura e o leitor). Inúmeros movimentos artísticos buscaram aplicar a tipografia cinética em suas composições. No Cubismo, Guillaume Apollinaire tratava a tipografia não apenas como elemento de linguagem verbal, mas também como imagem, fazendo com que o texto fosse antes de tudo visto, para só depois ser lido. No futurismo, Fillipo Marinetti aplicava a tipografia cinética para criar sensação de movimento e velocidade em suas composições. Além desses movimentos, o De Stjil (Holanda, 1917), o Construtivismo Russo (Rússia, 1921) e o Dadaísmo (Suíça, 1916) também tiveram grande importância.

No entanto, foi no cinema que a tipografia cinética teve seu grande salto e pode se firmar como uma forma de comunicação muito mais intuitiva e atraente que a tipografia estática. Segundo Lee, Forlizzi e Hudson (2002) o primeiro uso da tipografia cinética aparece nos créditos de abertura de North by Northwest (1959) e Psycho (1960), longa metragens de Hitchcock, com aberturas desenvolvidas por Saul Bass.

A visibilidade que a tipografia cinética ganhou ao ser utilizada nessas produções gerou uma demanda por profissionais especializados, o que garantiu papel de destaque a designers como Saul Bass, Pablo Ferro e Maurice Binder, cujos trabalhos se destacaram entre os demais. Com o desenvolvimento da fotocomposição no final da década de 50, os tipos se tornaram muito mais fáceis de manipular, uma vez que agora eles eram muito mais flexíveis, podendo expandir-se e contrair-se livremente (BLACKWELL, 2004).

Além disso, iniciou-se a implementação do computador no ambiente de trabalho, o que deu abertura a diversas outras ferramentas que facilitaram o desenvolvimento de animações com tipografia cinética, como o surgimento de softwares de animação, como o Quantel, o Flash, dentre outros. Atualmente, os avanços tecnológicos vêm alterando a forma como as informações são recebidas, aceitas e interpretadas pela sociedade. É evidente que as pessoas estão cada vez mais expostas a um mundo repleto de mensagens e informações e que, consequentemente, é necessário que consigam assimilar mais depressa o conhecimento.

No entanto, toda essa evolução no acesso a informação não é paralela a evolução da capacidade das pessoas de interpretarem as mensagens que recebem: por 
mais que um indivíduo seja exposto a inúmeras mensagens ao mesmo tempo, é normal ao ser humano processar apenas uma mensagem de cada vez. Com tudo isso, fica evidente que a tipografia cinética não é apenas uma forma de entretenimento visual, mas uma poderosa ferramenta capaz de captar e direcionar a atenção do usuário, fazendo com que este tenha muito mais facilidade na interpretação e memorização da informação que está sendo transmitida.

\subsection{Classificações e abordagens da tipografia cinética}

Como Barbara Brownie (2007, p. 1, tradução nossa) explica, "a tipografia cinética pode variar tão selvagemente que as propriedades [...] tais como o movimento, nem sempre estão presentes em todas as formas de tipo cinético." Com isso é possível ter ideia do panorama em que a tipografia cinética se encontra. Inúmeros projetos de tipografia cinética utilizam, além de recursos técnicos diferentes, abordagens diferentes, o que torna um desafio propor uma classificação eficiente.

Algumas das formas mais usadas para classificar a tipografia cinética são as classificações de Brownie (tipografia em movimento e tipografia fluida), Stone e Harding (2006) que classificam a partir de três dimensões (semântica denotativa, cor e textura e forma) e a classificação de Michael Pick.

A classificação de Michael Pick se mostra a mais completa dentre todas. Pick classifica a tipografia cinética em quatro partes: (1) personificação da linguagem; (2) ilustração literal da linguagem; (3) embelezamento rítmico da linguagem e (4) distorção polimórfica da imagem. A personificação da linguagem diz respeito a animações onde, além de uma escolha criteriosa por um tipo que seja adequado a linguagem conceitual da peça gráfica, busca-se personificar as vozes do texto.

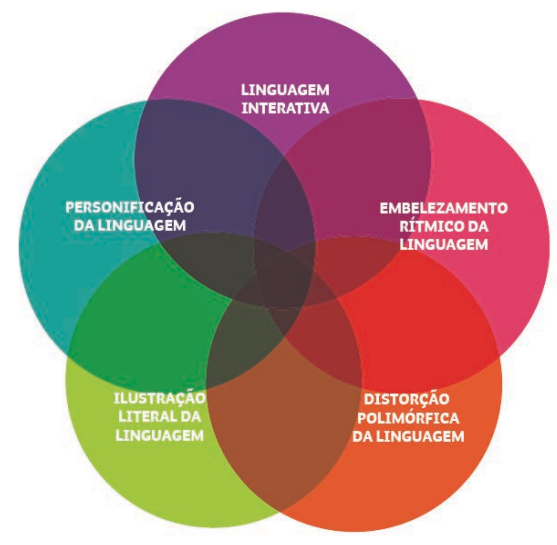

Figura 1 - Adaptação do modelos de classificação de Michael Pick, incluindo a abordagem baseada na linguagem interativa.

Fonte: Elaborado pelo autor, com base na pesquisa realizada.

Na ilustração literal da linguagem cria-se uma conexão entre o significado das palavras e sua forma literal. O embelezamento rítmico da linguagem se preocupa com o ritmo da animação, sendo que muitas vezes a legibilidade e a escolha tipográfica são deixadas em segundo plano. Por fim, a distorção polimórfica da imagem foca no movimento em si, na instabilidade da linguagem. Para Pick essa é a essência da 
tipografia cinética, uma vez que permite uma flexibilidade muito grande na variação formal das letras. Aqui se encaixam as animações que Barbara Brownie define como "tipografia fluída".

\subsection{Procedimentos metodológicos e método de pesquisa}

A Metodologia Científica pode ser caracterizada como (i) Aplicada, quanto à sua Natureza; (ii) Qualitativa quanto à Abordagem do problema; e (iii) Exploratória, quanto aos Objetivos. Do ponto de vista dos procedimentos técnicos, utiliza Pesquisa Bibliográfica, Revisão de Literatura com Redação Compilatória.

Como método de pesquisa, foi desenvolvido por Rodrigues (2012) um modelo de estudo dos princípios da tipografia cinética baseado nas propostas de Daniel Goscha (2005, apud RAMOS, 2008), Soo Hostetler (2006) e Rodrigues, Videira e Carvalho (2008).Goscha e Rodrigues, Videira e Carvalho apresentam metodologias complexas e bastante completas, no entanto, seu foco de estudo é a tipografia tradicional e as possibilidades oferecidas pelos softwares de animação disponíveis atualmente. O modelo de Hostetler, por outro lado, aborda muito mais a fundo a tipografia cinética, mas acaba deixando de lado questões relevantes que são abordadas pelos outros autores.

A metodologia de estudo desenvolvida subdivide a tipografia cinética em três partes: tipografia, espaço e tempo. Em tipografia estão inclusos os itens alteração, legibilidade, leiturabilidade e elementos auxiliares (pontuação visual, cor, luz, som e interação). No item espaço tem-se quadros, dimensionalidade (representação espacial e movimentos de câmera) e composição (princípios de composição em sequência). Por fim tempo reúne duração, ritmo, movimento (direção, velocidade, rotação e princípios da animação) e sequência (hierarquia da informação e transições). Neste modelo, elementos de estudo tipográfico, tais como variações de tipos, espacejamentos, etc., não são abordados. Considera-se que o usuário que busca mais informações a respeito da tipografia cinética já possui noções básicas da tipografia tradicional.

\subsubsection{Tipografia}

\subsubsection{Alteração}

Alterar a forma das letras é um dos métodos mais utilizados para enfatizar o significado de alguma palavra, contextualizar ou ilustrar uma frase. Por isso a "alteração" é a primeira questão que deve ser observada na tipografia. Além de alterar a forma das letras, também é comum fazer pequenas alterações em seu desenho a fim de tornar o movimento mais real, técnica comum em animações.

Para Rodrigues, Videira e Carvalho (2008), a alteração pode se dar por distorção ou por elaboração. Distorção refere-se ao movimento em que a base formal das letras é destruída, enquanto elaboração diz respeito a alterações onde apenas há adição de novas características formais a letra.

Yin Yin Wong (1988), no entanto, propõe que a alteração pode ser subdividida em transição e deformação, sendo que em ambas as categorias ocorre alteração da estrutura formal da tipografia. O quesito de diferenciação que Wong usa é a alteração 
da identidade visual da letra: quando uma letra é deformada e se transforma em outra (transformação da letra "F" em "R", por exemplo) ocorre transição; já quando a letra sofre algum tipo de distorção (como ser alongada, por exemplo), ocorre deformação.

\subsubsection{Legibilidade}

Relacionada com a percepção e com a velocidade de leitura e clareza na identificação dos caracteres, a legibilidade está diretamente ligada à compreensão das palavras. Há inúmeros fatores que influenciam na legibilidade dos caracteres. Klein (2008) cita fatores como contorno, estilo, inclinação, cor, contraste, etc.

Na tipografia cinética, no entanto, há vários outros fatores que devem ser considerados, uma vez que a tela oferece uma série de variáveis.

Matthias Hilnner (2007, apud BROWNIE, 2007) afirma que a letra que sofre alterações na animação não deve ser legível apenas no momento em que se apresentar inteira, mas também no espaço de tempo em que está entrando em foco, ou, pela linguagem cinematográfica, "entrando em cena".

\subsubsection{Leiturabilidade}

Mário César (s/d apud FONSECA, 2008) explica que "um texto legível não é necessariamente um texto confortável de ser lido", o que infere que leiturabilidade diz respeito ao conforto visual do texto, uma vez que ela se refere a todo o contexto em que o texto esta inserido, não focando apenas em características referentes a estrutura formal das letras, mas também a composição da mancha gráfica, a dificuldade do vocabulário, a estrutura frasal, etc.

Na tipografia cinética devem ser considerados a quantidade de palavras na tela e a velocidade em que elas ficam visíveis. Para Jun (2000) o ritmo é o principal fator a ser considerado para melhorar a leiturabilidade, segundo ele "o ritmo apropriado pode fazer a mensagem claramente compreensível e leiturável (JUN, 2000, p. 20, tradução nossa)".

\subsubsection{Elementos Auxiliares}

Elementos auxiliares são fatores que não são essenciais a tipografia cinética, mas quando utilizados com coerência garantem a esta maior notoriedade. Pela classificação de Rodrigues (2012), há cinco itens considerados elementos auxiliares: (i) pontuação visual; (ii) cor; (iii) luz; (iv) som e (v) interação.

i. Pontuação visual: diz respeito à utilização de elementos gráfico-visuais que servem para apoiar e reforçar os conceitos que a animação busca transmitir. ii. Cor: traz grande influência na tipografia cinética, devido não apenas a características psicológicas, mas também à legibilidade e leiturabilidade. iii. Luz: O componente luz na tipografia cinética é responsável em grande parte pela ambientação, dando à animação características que reforçam a mensagem que está sendo transmitida. iv. Som: tem grande influência na acepção da animação. Por ser um componente baseado no tempo, tem forte ligação com o movimento das formas. 


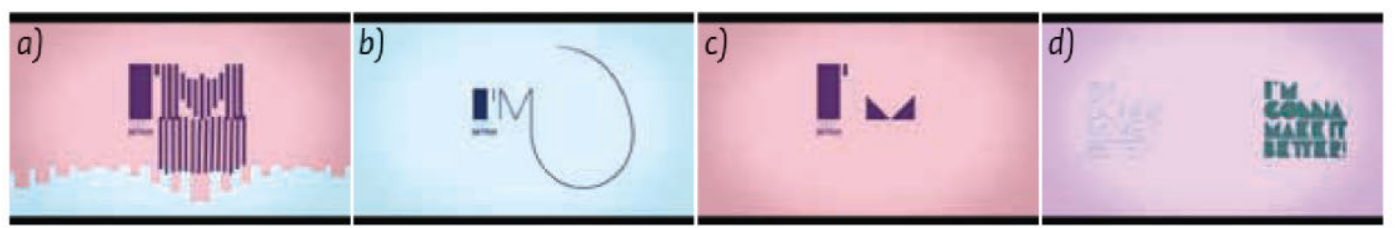

Alteração: Tipografia cinética Make it better, feita por Sebastian Baptista. Exemplos de a) distorção, b) elaboração por expansão, c) elaboração por subtração e d) elaboração por repetição. Fonte: Vimeo (2011)

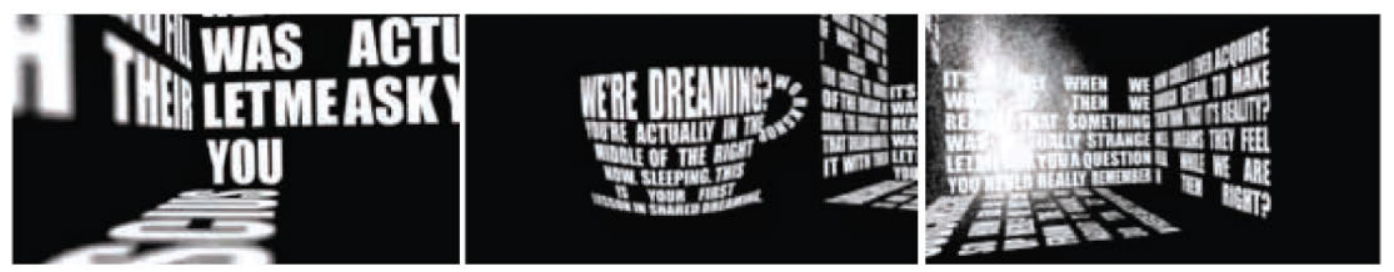

Leiturabilidade: Tipografia cinética de uma cena do filme Inception. Nesse exemplo, a grande quantidade de textos na tela, a velocidade de transmissão do conteúdo, os ângulos e distorções tornam o processo de leitura difícil. Nesse caso, as letras servem apenas como recurso visual para acompanhar o ritmo das falas do diálogo. Fonte: Youtube (2011)
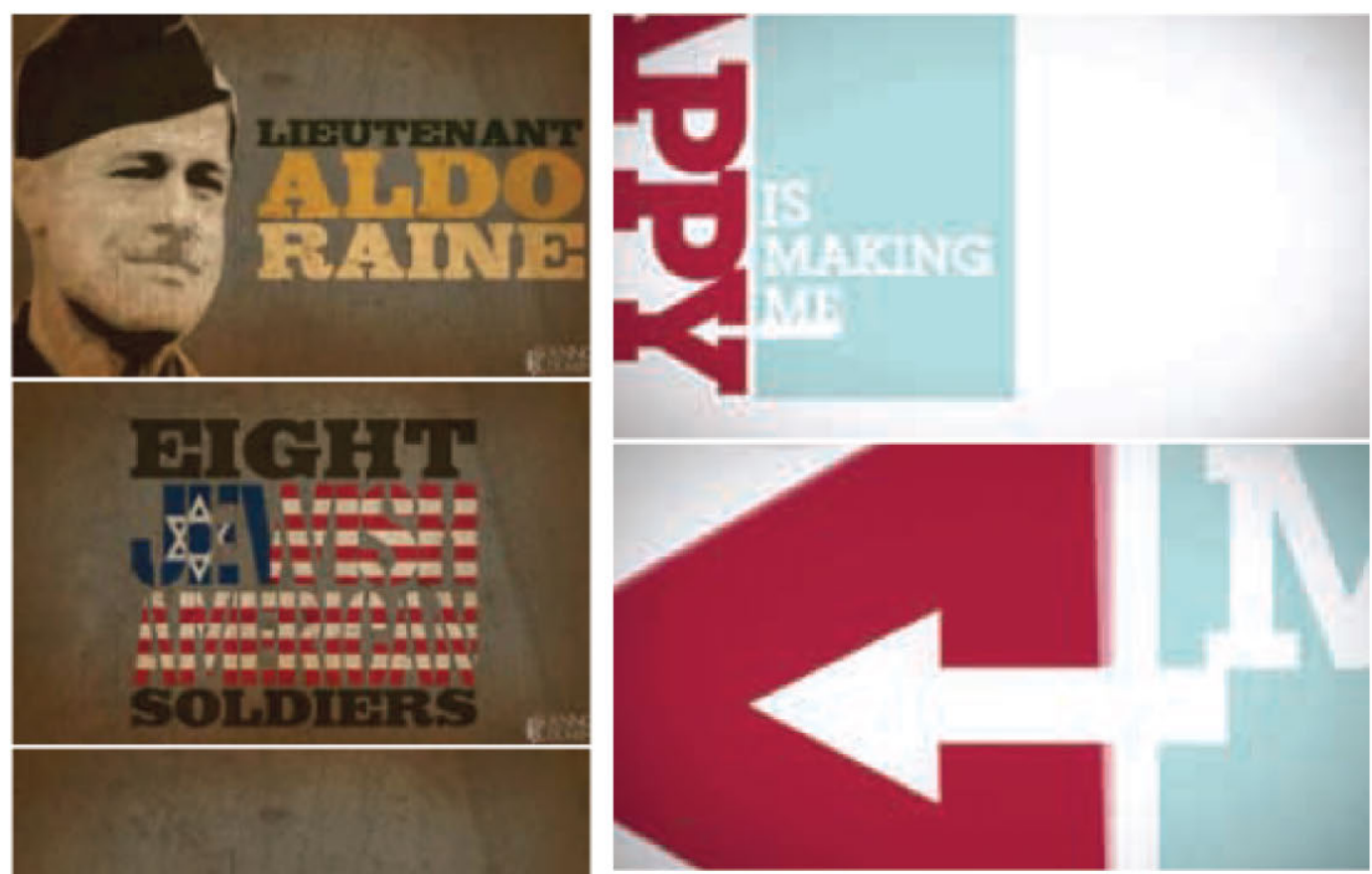

Sequência: Quadros da animação A very vimeo valentine, de Doug Chang (2010). É utilizado o espaço negativo existente entre a abertura do Y e o retângulo, que forma uma seta. A seta aponta para a esquerda, direcionando o olho do espectador para esse lado. A unidade é criada pela paleta de cores e as formas geométricas, tanto dos elementos auxiliares quanto da tipografia escolhida. Fonte: Vimeo (2011)

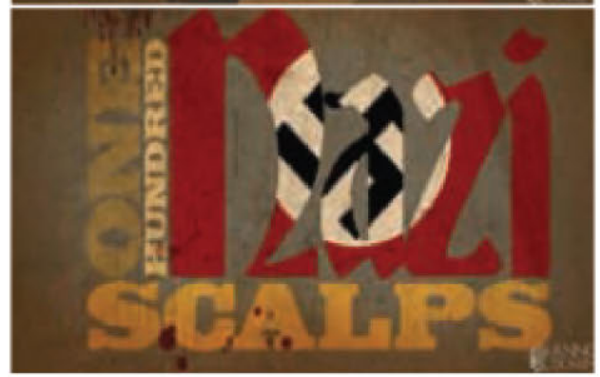

Cor: Tipografia cinética feita com uma cena do filme Bastardos Inglórios, por Anno Domini (2010). As cores utilizadas no texto remetem aos uniformes usados pelos soldados. As cores das bandeiras são utilizadas nas palavras jewish american, france e nazi, e mesmo que o espectador não leia a mensagem, pode saber que se trata de uma narrativa sobre guerra envolvendo judeus-americanos, franceses e nazistas. Devido ao baixo contraste com o fundo, às estampas das bandeiras nas palavras e à velocidade com o que o texto é trasmitido, a legilidade e a leiturabilidade tornam-se comprometidas. Porém, nesse caso, o texto é apenas uma ilustração da mensagem sonora, servindo mais para ser visto que para ser lido. Fonte: Youtube (2011)

Figura 2 - Exemplos de princípios relacionados à tipografia

Fonte: Elaborado pelo autor, com base na pesquisa realizada. 
Devido à relação do som com a forma, com a cor e com o movimento da composição, ele contribui para dar notoriedade ao impacto emocional da animação, trazendo consigo harmonia e aumentando o apelo visual e sensorial do projeto, como afirma Hostetler (2006). v. Interatividade: é pouco utilizada, mas é considerada como uma das soluções para um dos maiores problemas da tipografia cinética: seu caráter efêmero. Como normalmente o leitor não interage com as animações, adquirindo caráter passivo, pode acabar se distraindo e ao término do vídeo o conteúdo não é assimilado.

\subsubsection{Espaço}

\subsubsection{Quadros}

Quadro ou frame são as imagens que, quando reproduzidas em sequência dentro de determinado espaço de tempo, compõem a animação. Em animações o tempo é medido através de frames por segundo (fps), sendo que é esta taxa que determina a velocidade máxima que uma animação pode reproduzir para criar a impressão de movimento contínuo e suave, conforme Krasner (2008). Atualmente se utilizam duas proporções principais: fullscreen (4:3) e widescreen (16:9), considerado o "formato do futuro" por ser o padrão da maioria dos dispositivos eletrônicos. A utilização cada vez mais comum do formato widescreen se deve ao fato de que ele se assemelha ao formato de visão do olho humano (LAMDIM, 2009).

\subsubsection{Dimensionalidade}

Referente à localização espacial dos componentes da tipografia cinética, esta pode ser bidimensional ou tridimensional. Destacam-se dois itens de estudo: (i) representação espacial e (ii) movimentos de câmera. Rodrigues, Videira e Carvalho (2008) afirmam que a representação espacial pode ser feita tanto por meio do uso de elementos auxiliares como dando às letras características de entidade físicas.

Considerando os estudos de Rodrigues, Videira e Carvalho (2008) aliados às pesquisas de Block (2008) pode-se definir as formas de representação espacial mais relevantes à tipografia cinética: sombra, escala, difusão atmosférica, sobreposição e perspectiva. Os movimentos de câmera dizem respeito à forma através da qual os planos em movimento serão vistos, servindo para simular o ponto de vista, diminuindo ou aumentando a intensidade visual, conforme afirma Bruce Block (2008). Esses movimentos podem se dar basicamente de três formas: aproximação/ afastamento, rotação a partir de um eixo ou deslocamento no espaço.

\subsubsection{Composição}

Krasner (2008, p. 215, tradução nossa) define composição como "o projeto a partir do qual os elementos são organizados". Quando se trabalha com animação, deve-se considerar que além do plano espacial há também o plano temporal do projeto, ou seja, é necessário planejar a modificação da composição ao longo do 
tempo. Assim como na tipografia tradicional, na tipografia cinética deve ser desenvolvida uma grade e margens adequadas ao projeto.

\subsubsection{Tempo}

\subsubsection{Duração}

O tempo de exposição de cada elemento na tela é extremamente importante na tipografia cinética, pois como Rodrigues, Videira e Carvalho (2008, p. 56) afirmam, "influencia o ritmo de leitura e pode enfatizar uma determinada palavra e estabelecer uma hierarquia dentro da mensagem". Considerando que na tipografia cinética as letras se comportam como ilustrações literais da linguagem, é importante que assim como na animação clássica seja considerado o timing, princípio que impõe as formas leis físicas comuns na natureza, como a velocidade de aceleração dos corpos, etc.

\subsubsection{Ritmo}

Segundo Block (2008) para haver ritmo são necessários três elementos básicos: alternância, repetição e andamento. Paralelo a este autor, Jun (2000) afirma que o ritmo na tipografia é organizado de forma semelhante a como é feito na música, e apropriando-se da classificação de Creston (1964, apud JUN, 2000) afirma que o ritmo é composto por quatro elementos: (i) métrica, (ii) passo, (iii) acento e (iv) padrão.

\subsubsection{Movimento}

Na tipografia cinética o movimento auxilia a captar a atenção do leitor e torna o processo de comunicação mais efetivo, pois, segundo Arnhein (1980) ele implica em alterações ou mudanças no espaço que, por instinto, tendem a provocar reações em quem às percebe. O movimento reúne quatro itens de estudo: (i) direção; (ii) velocidade; (iii) rotação e (iv) princípios da animação. Direção, para Block (2008) pode ser horizontal, vertical, diagonal ou circular, e a trajetória dos movimentos pode ser retilíneo ou curvilíneo, implicando diretamente nas características emocionais associadas a linhas retas ou curvas.

A velocidade, espaço de tempo que um elemento leva para ir de um ponto a outro, influencia na intensidade visual da mensagem, pois determina o dinamismo e naturalidade dos movimentos. Além disso, como Delicado (2009) e Hostetler (2006) afirmam em seus estudos, a sutileza ou celeridade dos movimentos pode intensificar os sentimentos que a mensagem deseja comunicar. Segundo Delicado (2009), podemos classificar a rotação em relação ao sentido, a velocidade e ao eixo de rotação. Rodrigues, Videira e Carvalho (2008) também a classificam em relação ao espaço, onde ela pode ser plana e espacial. Os princípios de animação dizem respeito a um conjunto de técnicas desenvolvidas pelos animadores dos estúdios Disney que buscam deixar os movimentos mais realistas através de pequenas deformações no desenho das formas. 


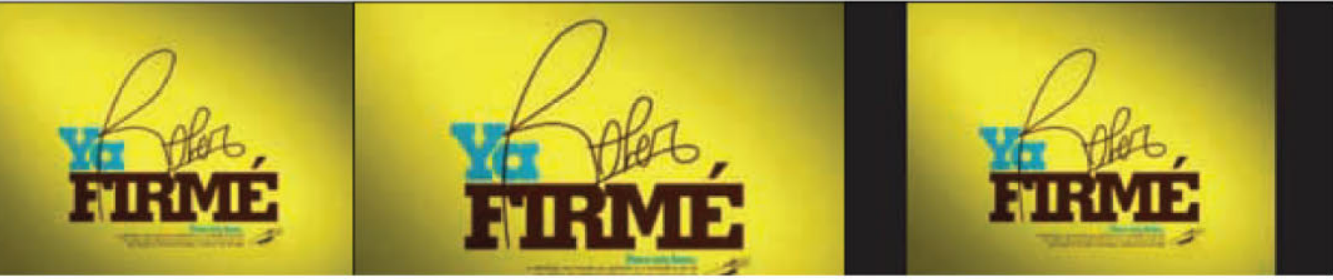

Proporção: Quadro do clipe Ya no sé qué hacer conmigo (Milagrito Films, 2007), feito em proporção 4:3. O primeiro exemplo mostra a animação em uma tela fullscreen e, os outros dois mostram a sua adaptação para uma tela widescreen, cortada ou com faixas laterais. Fonte: Da autora, com vídeo retirado do Youtube (2011)

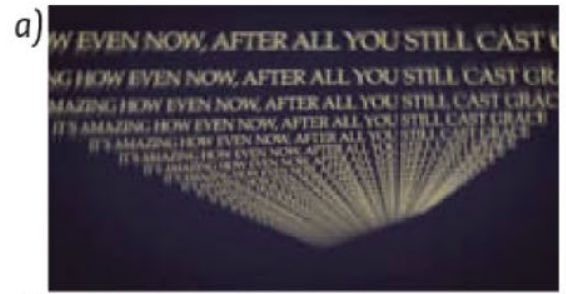

b)

c)
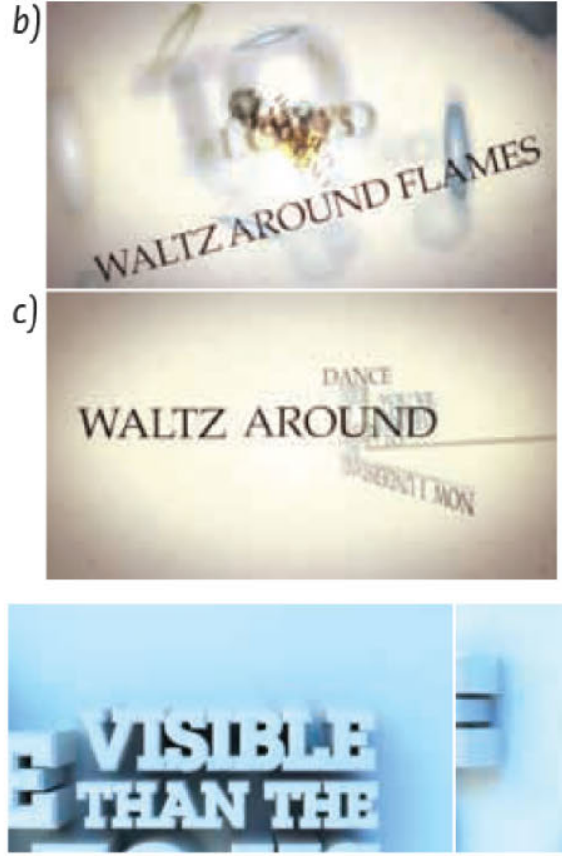

Representação Espacial: Decoy: Run - Waltz Around Flames kinetic typography (2011), Nesse vídeo a) mudanças de escala, b) difusão atmosférica e c) sobreposições são utilizadas para criar profundidade. Fonte: Vimeo (2011)

Movimento de câmera: The Social Network "Going Live" Typography, de Jorge Sandoval (2010). A sequência superior mostra um exemplo de travelling vertical revelando o texto escrito em coluna. A sequência inferior mostra um travelling horizontal. Nesse último, a câmera acompanha o movimento do retângulo branco, que, portanto, permanece fixo em relação ao quadro enquanto os outros elementos deslocam-se. Fonte:Vimeo (2011)
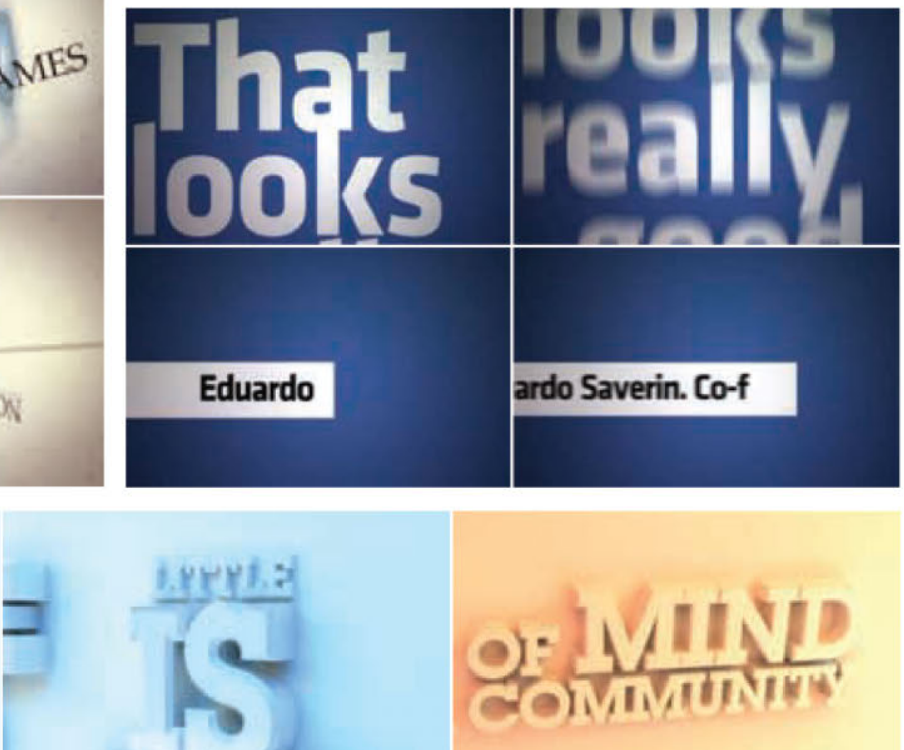

Representação Espacial (perspectiva): Quadros de Terence McKenna- Community of mind Kinetic Typography, de Olivier Ferland (2011). Apresenta exemplos de perspectiva de um, dois e três pontos (respectivamente). Fonte: Vimeo (2011)

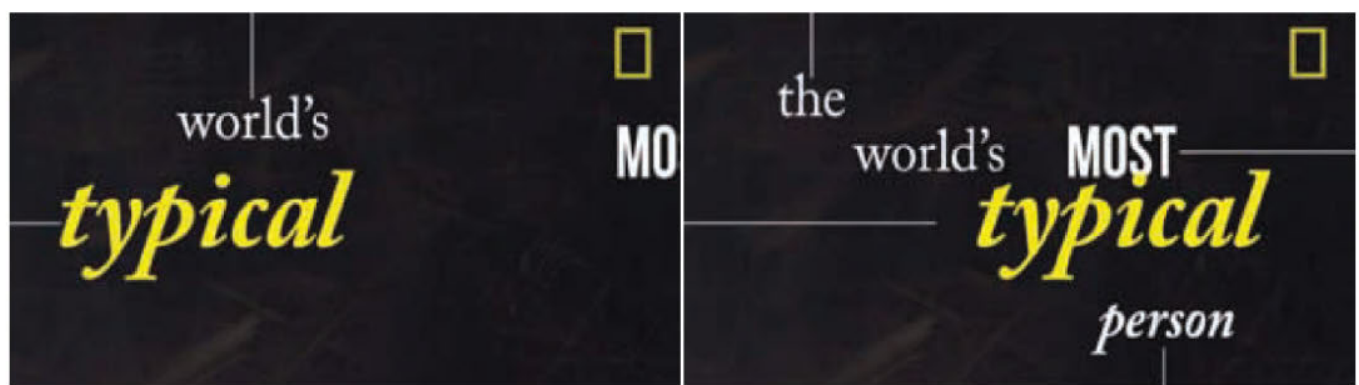

Sequência: Sequência da animação 7 Billion: Are You Typical?, produzida pela National Geographic Magazine (2011). Nesse exemplo, as palavras surgem por ordem de importância para o entendimento da frase, e são destacadas pela alteração nos fatores tipográficos, tais como peso, postura, tamanho, contraste e cor das palavras. A palavra typical, mais importante na frase, permanece por mais tempo na tela, enquanto as outras são retiradas. Fonte: Youtube (2011)

Figura 3 - Exemplos e princípios relacionados ao espaço e ao tempo.

Fonte: Elaborado pelo autor, com base na pesquisa realizada. 


\subsubsection{Sequência}

Uma animação que usa de tipografia cinética apresenta inúmeras cenas e elementos visuais animados dentro de espaços específicos de tempo. À disposição e ligação entre todos esses elementos e cenas dá-se o nome de sequência. A sequência agrupa dois itens de aprendizagem: (i) hierarquia da informação e (ii) transições. A hierarquia da informação diz respeito ao sistema que define como as informações serão dispostas dentro da área de trabalho do projeto, sendo este sistema o responsável por grande parte da percepção e facilidade de leitura que o usuário terá futuramente. Rodrigues, Videira e Carvalho (2008) destacam que na tipografia cinética a ênfase costuma ser dada a palavras chave, uma vez que demais elementos entram apenas como grafismos de apoio à informação principal.

As transições servem para enfatizar a conclusão de uma ação e fazer a ligação com a próxima, conforme definem Rodrigues, Videira e Carvalho (2008), citando três transições que podem ser usadas com grande eficiência em animações com tipografia cinética: desvanecer, limpar e cortar. Além disso, Rodrigues (2012) complementa a lista com o efeito zoom, que embora não esteja presente na lista dos autores é comumente observado nesse tipo de trabalho.

\section{CONCLUSÃO}

Atualmente é vivenciado um momento de grande volume de informações, o que gera uma demanda por tecnologias capazes de se comunicar no ritmo que os usuário desejam sem deixar de lado a eficiência na transmissão do conteúdo.

A maior contribuição dessa pesquisa foi o método de estudo desenvolvido. Através dos estudos de Daniel Goscha (2005, apud RAMOS, 2008), Soo Hostetler (2006) e Rodrigues, Videira e Carvalho (2008), foi possível desenvolver uma organização dos princípios da tipografia cinética.

Além de reordenar fatores já citados por outros autores, o elemento "interação" foi adicionado ao modelo, uma vez que cada vez mais vem sendo usado para aprimorar o processo de compreensão e assimilação do conteúdo apresentado pela tipografia cinética.

Através desse esquema organizacional, o processo de aprendizagem da tipografia cinética se tornou muito mais claro. Além disso, se evidenciou ainda mais a necessidade de integrar ao estudo desta área não apenas características técnicas (relacionadas com os softwares de animação), mas também um estudo dos princípios elementares da tipografia e da teoria da animação, preparando os Desenhadores para este novo método de apresentação textual de informações.

Inferiu-se que a tipografia cinética é uma área em franca expansão, com possibilidades de criação quase infinitas (o que chega, inclusive, a dificultar seu estudo e classificação), e embora demande de mais tempo que um projeto gráfico tradicional, as possibilidades de comunicação e interação são muito mais notórias.

Mediante a pesquisa executada, foi desenvolvido um extenso material de estudo para entusiastas da tipografia cinética. Com isso, espera-se que este material 
possa servir de base para projetos e pesquisas que envolvam esta nova forma de comunicação.

\section{REFERÊNCIAS}

BLOCK, Bruce. The visual story: creating the visual structure of film, TV and digital media. Oxford: Focal Press, 2008. 2a ed.

BRINGHURST, R. Elementos do estilo tipográfico. São Paulo: Cosacnaify, 2005.

BROWNIE, Barbara. One Form, Many Letters: Fluid and transient letterforms in screenbased typography artefacts. Reino Unido: University of Hertfordshire, MeCCSA Postgraduate Network Conference, 2007. Disponível na internet por http em: <http://www.fluidtype.org/MeS SCA_Brownie_FluidType.pdf> Acesso em: 8 jun. 2011.

HILLNER, Matthias. Virtual Typography. Switzerland: AVA Publishing, 2009. Disponível na internet por http em: <http://www.turmadod.com/alunos/downloads/3s2010_ 1/computacao2/virtual_typography.pd f> Acesso: 13 abr. 2011.

HOSTETLER, S.C. Integrating Typography and Motion in Visual Communication. Cedar Falls, IA, EUA: University of Northern lowa, 2006. Disponível na internet por http em: $<$ http://www.units.muohio.edu/codeconference/paprs/papers/soo\%20hostetler20 06\%20idmaa\%20full\%20paper.pdf> Acesso em: 07 abr. 2011.

JUN, S. Non-linear Expressions Using Interactive Kinetic Typography. Pennsylvania: Carnegie Mellon University, 2000. Disponível na internet por http em: <http://www.contrib.andrew.cmu.edu/ soojin/documents/Jun_2000_interactive_KT.p df> Acesso em: 13 abr. 2011.

KLEIN, S. P. Conseguindo boa legibilidade e "leiturabilidade" na Web. Imasters, 2011. Disponível na internet por http em: <http://imasters.com.br/artigo /20444/design/conseguindo-boa-legibilidade-eleiturabilidade-na-web> Publicado em: 12 abr. 2011 Acesso em: 21 mai. 2011.

KRASNER, J. Motion graphics: applied history and aesthetics. Oxford: FocalPress, 2008.

LEE, Johnny; FORLIZZI, Jodi; HUDSON, Scott. The Kinetic Typography Engine: An Extensible System for Animating Expressive Text. CHI Letters: UIST'02, 2002. V: 4, Issue: 2, Pages: 8190. Disponível na internet por http em: <http://www.cs. cmu.edu/ johnny/academic/KT_Engine_UIST200 2.pdf> Acesso em: 18 abr. 2011.

LUPTON, Ellen. Pensar com tipos. São Paulo: Cosac Naify, 2006.

RODRIGUES, Luis; VIDEIRA, Mario; CARVALHO, Susana. Tipografia em movimento: Dimensão metafórica. Lisboa: Faculdade de Belas Artes da Universidade de Lisboa, 2008. Disponível na internet por http em: <http://issuu.com/scarvalho/doc s/livro_visualiza_o_online_> acesso em: 24 out. 2010.

RODRIGUES, Mariane Alves. 0 livros das espécies tipográficas: a tipografia cinética aplicada ao desenvolvimento de um conteúdo didático para iPad. Universidade Federal de Santa Maria, 2012. Trabalho de conclusão de Curso.

SALTZ, I. Design e tipografia: 100 fundamentos design tipos. São Paulo: Blucher, 2010. 